\title{
Growth response of wheat and associated weeds to plant antagonistic rhizobacteria and fungi
}

\author{
Adnan Mustafa, ${ }^{1,2}$ Muhammad Naveed, ${ }^{2}$ Tanveer Abbas, ${ }^{1}$ Qudsia Saeed, ${ }^{3}$ Azhar Hussain, ${ }^{4}$ \\ Muhammad Nadeem Ashraf, ${ }^{1}$ Xu Minggang ${ }^{1}$ \\ ${ }^{1}$ National Engineering Laboratory for Improving Quality of Arable Land, Institute of Agricultural \\ Resources and Regional Planning, Chinese Academy of Agricultural Sciences, Beijing, P. R. China; \\ ${ }^{2}$ Institute of Soil and Environmental Sciences, University of Agriculture, Faisalabad, Pakistan; \\ ${ }^{3}$ College of Natural Resources and Environment, Northwest Agriculture and Forestry University, Yangling, \\ P. R. China; ${ }^{4}$ Department of Soil Science, University College of Agriculture and Environmental Sciences, \\ The Islamia University of Bahawalpur, Pakistan
}

\begin{abstract}
Wheat is the staple cereal crop of Pakistan but its growth is rigorously affected by associated weeds. Present study evaluated the synergistic effect of plant antagonistic rhizobacteria and fungi on growth, yield and suppression of wheat-associated weeds. Wheat associated weeds Phalaris minor and Avena fatua were grown in pots containing wheat as well. Pseudomonas aeruginosa strain PAO1 and Trichoderma harzianum T-MN6 were used as amendments to check their effect on two major weeds of wheat. The combined application of PAO1 and T-MN6 reduced the shoot length of Phalaris minor up to $30 \%$ and Avena fatua $40 \%$, root length $22 \%$ and $28 \%$, fresh biomass $29 \%$ and $31 \%$ respectively over their sole application. Similarly, inoculation of PAO1 and T-MN6 alone and in combination considerably enhanced
\end{abstract}

Correspondence: Xu Minggang, Institute of Agricultural Resources and Regional Planning, Chinese Academy of Agricultural Sciences, Haidian, 100081 Beijing, China; and Muhammad Naveed, Institute of Soil and Environmental Sciences, University of Agriculture, Faisalabad, Pakistan.

E-mail: xuminggang@caas.cn; muhammad.naveed@uaf.edu.pk

Key words: Pseudomonas aeruginosa; Trichoderma harzianum; Phalaris minor; Avena fatua, biological weed control; wheat growth.

Acknowledgements: the authors gratefully acknowledge the Ayub Agriculture Research Institute Faisalabad, Pakistan for facilitating to conduct this study. The authors are thankful to Environmental Sciences Laboratory Institute of Soil and Environmental Sciences, University of Agriculture, Faisalabad Pakistan.

Received for publication: 8 April 2019.

Revision received: 16 July 2019.

Accepted for publication: 23 July 2019.

${ }^{\circ}$ Copyright: the Author(s), 2019

Licensee PAGEPress, Italy

Italian Journal of Agronomy 2019; 14:1449

doi:10.4081/ija.2019.1449

This article is distributed under the terms of the Creative Commons Attribution Noncommercial License (by-nc 4.0) which permits any noncommercial use, distribution, and reproduction in any medium, provided the original author(s) and source are credited. growth, yield and physiological parameters of wheat. It was inferred from this study that the synergistic application of PGPR and fungi is a promising option to suppress major weeds of wheat and to enhance growth and yield of wheat.

\section{Introduction}

Wheat (Triticum aestivum L.) is the most common staple food in the world with the average production of 672 million tons in 2012 (FAO, 2014). In Pakistan it occupies a substantial place due to the largest area under single crop cultivation. The average yield of wheat in Pakistan does not exceed $30-35 \%$ of its potential compared with the higher yields in other wheat growing countries (Khan et al., 2002). Plants are continuously exposed to different biotic (pathogens, insects and weeds) and abiotic (temperature, precipitation and limited nutrients) stresses which leads to reduction in crop yields (Mustafa et al., 2019). Of all other yield determining factors attack by weeds is a most damaging and costly factor in crop production (Noorka and Shahid, 2013). Among other crop pests weeds cause higher yield reductions (Oerke et al., 2006).

In conventional times, weeds were controlled by traditional agronomic and chemical methods. However, there are certain merits and demerits of using such conventionally outdated methods. No doubt herbicides get famed in weed control due to their rapid response upon application, variety of available chemicals and application practices, energy efficiency and lesser costs (Ghorbani et al., 2005). Continuous use of chemical herbicides causes contamination of water bodies and pollute natural resources like air, soil and plants thus have damaging effects on non-target species such as wildlife (Geiger et al., 2010; Tabaglio et al., 2013). Herbicide residues are another serious threat in food and environment related concerns (Crone et al., 2009). Similarly, hand weeding is a labour-intensive job, hence cannot be applied on a larger scale. Accordingly, new weed control strategies that are safe, cost effective and environmentally sound are needed. In this context, biological control using bacteria and fungi could be a valuable approach in management of noxious weeds (Mustafa et al., 2019).

Different bacterial genera residing in rhizosphere that are widely involved in several biological activities such as sustainability of soil ecosystems and nutrient dynamics are called rhizobacteria (Ahemad and Kibret, 2014). Apart from direct plant growth promotion mechanisms these rhizobacteria differentially colonise in the rhizosphere and produce an array of phytotoxic 
metabolites that suppress germination and growth of certain plants hence are termed as plant antagonistic bacteria (Sturz and Christie, 2003). A major group of rhizobacteria with potential for biocontrol of weeds is Pseudomonads. A number of Pseudomonas strains exhibit plant growth promotional activities via production of phytoharmones, solubilisation of phosphate and other nutrients (Vyas et al., 2009; Ali et al., 2017), production of siderophores and antibiotics such as, phenazines, pyrrolnitrin and pyoluteorin, diacetylphloroglucinol (2,4-DAPG) and biocidal compounds hydrogen cyanide (Raaijmakers et al., 2002) and cell wall degrading enzymes (Haas and Defago, 2005).

Trichoderma spp. are most frequently characterised soil borne fungi equipped with several mechanisms to utilise diverse substrates and to survive under plenty of unfavourable chemical compounds in soil-plant-root systems (Harman et al., 2004). To- date most of the literature on Trichoderma spp. had concentrated their role as biological control agent against nematode and fungal diseases and other plant pathogens including invertebrates and bacteria (Sahebani and Hadavi, 2008; Hanada et al., 2009). Whereas, scarce reports are available on biological weed control using Trichoderma spp. and the scanty available reports are merely confined to Trichoderma virens (Heraux et al., 2005). Most obvious underlying mechanisms of Trichoderma spp. as biocontrol agents include: mycoparasitism, competition, antibiosis, induced plant defence and production of cell wall lytic enzymes (Howell, 2003). A so-far unexploited category of microorganisms is the use of rhizobacteria and Trichoderma spp. for biological weed control.

In our previous studies, the plant antagonistic rhizobacterial strains were used to suppress wheat associated weeds (Abbas et al., 2017b). In present study, we hypothesised that the synergistic use of plant antagonistic rhizobacteria and fungi may have differential effects on wheat and its associated weeds. Therefore, rhizobacterial strain PAO1 characterised as (Pseudomonas aeruginosa) inhibitory to weeds but not to wheat and a fungus T-MN6 (Trichoderm harzianum) were used in consortium to check their bio herbicidal potential against major weeds of wheat and their effects on wheat. These agents were applied in pots containing wheat and weeds (Avena fatua) and (Phalaris minor).

\section{Materials and methods}

\section{Collection of plant antagonistic rhizobacterial and Trichoderma strain}

393 strains of presumed rhizobacterial plant antagonists were isolated from wheat fields heavily infested with associated weeds across District Faisalabad, Pakistan. These strains were isolated from rhizosphere of both the wheat as well as its associated weeds. The strains were tested in vitro for production of phytotoxic substances and in vivo to check their effects inhibitory on weeds and growth promoting effects in wheat in sterilised agar plates in our previous studies (Abbas et al., 2017a, 2017b). Whereas, the previously isolated plant growth promoting fungus Trichoderma harzianum T-MN6 was friendly donated by Plant Pathology Department, University of Agriculture, Faisalabad, Pakistan that was further purified in laboratory. In present study, based on the efficiency to inhibit germination (data not shown) and growth of weeds the rhizobacterial Pseudomonas aeruginosa PAO1 strain was selected to further test its inhibitory effect on two major weeds of wheat (Avena fatua and Phalaris minor) in synergism with previously isolated and purified plant growth promoting fungus
(Trichoderma harzianum T-MN6) under weedy and weed free pot conditions.

\section{Culture preparation and mycelial suspension}

For Pseudomonas aeruginosa PAO1 the culture containing strains was prepared in (King's B broth) and stored in Erlenmeyer flasks (King et al., 1954). Mature Growth of the strain was then transferred to flasks using sterilised bacteriological loop, following incubation in a shaking incubator (Firstek Scientific, Tokyo, Japan) at $100 \mathrm{rev}$. per minute for $48 \mathrm{~h}$ at $28 \pm 1^{\circ} \mathrm{C}$. The optical density (O.D) of the prepared culture was then measured using a spectrophotometer (Nicolet Evolution 300 LC, Cambridge, UK) at (wavelength $600 \mathrm{~nm}$ ), and adjusted to 0.5 to attain an identical population of bacteria $\left(10^{8}-10^{9} \mathrm{cfu} \mathrm{mL}^{-1}\right)$. Whereas, for Trichoderma harzianum T-MN6 culture was prepared on sterile potato dextrose broth in Erlenmeyer flasks and incubated for 8 days at $27^{\circ} \mathrm{C}$ and $160 \mathrm{rpm} \mathrm{min}^{-1}$ (Javaid and Adrees, 2009). The culture of Trichoderma harzianum T-MN6 was then filtered to obtain culture filtrates and residue (mycelia). The mycelia were then washed three times by sterile water followed by dilution with sterile distilled water to maintain uniform concentration of $\left(10^{6}\right.$ $10^{7}$ mycelia $\mathrm{mL}^{-1}$ ).

\section{Inoculation}

Inoculum of the Pseudomonas aeruginosa strain PAO1 and Trichoderma harzianum T-MN6 were mixed with three times autoclaved and sterilised peat at the ratio of 1.25:1 followed by incubation at $28 \pm 1^{\circ} \mathrm{C}$ for overnight. Seed coating of $A$. fatua, $P$. minor and wheat were performed using a mixture containing inoculated peat and sterilised sugar solution. Whereas, only wheat seeds were dipped in broth to maintain a weed free control. Inoculated fifteen viable seeds of $A$. fatua and $P$. minor were seeded together below soil surface under pot condition. After that, $25 \mathrm{~mL}$ fresh culture of selected bacterial strain and $25 \mathrm{~mL}$ mycelial suspension of Trichoderma harzianum T-MN6 were applied on soil surface of relevant pots sown with wheat and weeds followed by a thin surface layer of sand. For weed free control, $25 \mathrm{~mL}$ of King's B and potato dextrose broth were sprayed onto soil surface of pots followed by a thin apparent layer of sand (Vargas and O'Hara, 2006). All the pots were placed in rain protected wire house and maintained at field capacity.

\section{Experimental set up}

Present study was conducted in pots placed in wire house of Institute of Soil and Environmental Sciences, University of Agriculture, Faisalabad $\left(31.438976^{\circ} \mathrm{N}\right.$ and $\left.73.069029^{\circ} \mathrm{E}\right)$ to assess the ability of chosen plant antagonistic bacterial strain (Pseudomonas. aeruginosa PAO1) and plant growth promoting fungus (Trichoderma harzianum T-MN6) for suppression of wheat-associated weeds and subsequent enhancement of growth and yield of wheat. Pots with uniform diameter $30 \mathrm{~cm}$ were filled with air-dried and sieved soil at $8 \mathrm{~kg}$ per pot. There were four treatments (Control, PAO1, T-MN6 and PAO1 + T-MN6) replicated in triplicates. The pots were arranged in three sets, viz.: i) weed free conditions containing wheat only with a separate control; ii) Phalaris minor infested pots co-seeded with wheat having a $P$. minor containing control; iii) Avena fatua infested pots co-seeded with wheat having an A. fatua containing control. The merged soil sample was examined for different physico-chemical characteristics. The texture of soil was sandy clay loam (Typic Haplocambid), $\mathrm{pH} 7.4$, extract electrical conductivity (ECe) $1.5 \mathrm{dS} \mathrm{m}^{-1}$, saturation percentage $30.2 \%$, organic matter $0.88 \%$, total $\mathrm{N} 0.037 \%$, avail- 
able P $7.81 \mathrm{mg} \mathrm{kg}^{-1}$, and extractable $\mathrm{K} 158 \mathrm{mg} \mathrm{kg}^{-1}$. Seeds of wheat (Galaxy 2013) were collected from Department of Agronomy, University of Agriculture, Faisalabad and seeds of weeds were friendly donated by Ayub Agriculture Research Institute, Faisalabad. Clean seeds were dipped in water; floating seeds were discarded and the seeds settled in the bottom were taken for the trial. Eight seeds of wheat were sown in each pot. Fifteen seeds of $A$. fatua and $P$. minor were sown in each pot except weed free conditions. Pots were placed in the wire house under ambient light and temperature by using completely randomised design. Chemical fertilisers were applied as N, P and $\mathrm{K}$ at the rate of $120-90-60 \mathrm{~kg} \mathrm{ha}^{-1}$ as urea, diammonium phosphate and sulphate of potash, respectively. Whole PK fertilisers were applied at the time of sowing while $\mathrm{N}$ was applied in two splits. Data regarding growth and yield parameters were collected following standard procedure.

\section{Growth and yield parameters of wheat and weeds}

Data regarding growth and yield parameters including plant height, 1000-grains weight, root length, number of total tillers, productive tillers and spike length of wheat were recorded. Similarly, data regarding shoot length, root length and fresh biomass of weeds were recorded. Shoot length and root length were measured at the time of harvesting and uprooting the plant, respectively. Grain yield per pot was measured after harvesting the plant.

\section{Plant chemical analysis}

At physiological maturity grain samples of wheat were collected from pots for determination of nitrogen, extractable phosphorus and potassium. All the samples were ground and digested (Wolf, 1982). Total nitrogen was measured by using Kjeldahl ammonium distillation apparatus. Phosphorus was measured by adding $10 \mathrm{~mL}$ Barton reagent in $5 \mathrm{~mL}$ sample through spectrophotometer (T80 UV/VIS Spectrometer PG Instruments Ltd). Actual concentration of phosphorus was measured following standard curve. Potassium was simply measured by flame photometer (Jenway PFP-7, England) and its concentration was derived by using calibration curve.

\section{Physiology of plants}

Chlorophyll contents of wheat were measured using SPAD$502 \mathrm{~m}$ (Konica-Minolta, Japan) at 60 DAS. Values given by instrument are represented as SPAD values, and index directly related to chlorophyll contents in leaves (Coste et al., 2010).

Relative water content (RWC) of leaves was determined by using the following formula as described by Mayak et al. (2004).

Relative water content $=\quad$ Fresh weight - Dry weight $\times 100$ (RWC) Fully turgid weight - Dry weight
The fully turgid weight of leaf was taken after putting it in $100 \%$ humidity in the dark at $4^{\circ} \mathrm{C}$ for $48 \mathrm{~h}$.

\section{Statistical analysis}

Data regarding growth and NPK contents of infected wheat plants were analysed statistically following standard procedures. Means were compared to figure out significant differences among all treatments by using least significant difference test (LSD) test (Steel et al., 1997). All the statistical analyses were performed by using Statistix 8.1 using linear models.

\section{Results}

\section{Growth response of test weeds}

Data on growth parameters (Table 1) of both weeds indicated significant reduction in shoot length, root length and fresh biomass of the tested weeds upon sole and synergistic application of strain PAO1 and T-MN6 In Phalaris minor containing control (no amendment), the sole application of PAO1 and T-MN6 reduced the shoot length up to 20 and $11 \%$ respectively, whereas their effect was more obvious when these strains were applied in combination yielding 30\% reduction in shoot length as compared to control. Similarly, in A. fatua containing pots the separate application of PAO1 and T-MN6 reduced shoot length up to 20 and $16 \%$ as compared to respective controls, whilst these results are comparable with significant reduction of shoot length upon combined application resulting in $40 \%$ reduced shoot length of $A$. fatua. These results revealed shoot length of tested weeds was considerably reduced with the combined application of PAO1 and T-MN6 as compared to their sole application.

Alone inoculation of PAO1 and T-MN6 reduced root length of Phalaris minor up to 14 and $12 \%$ respectively, while the maximum reduction $(22 \%)$ resulted with co-inoculation of these isolates in Phalaris minor containing pots as compared to respective controls. Likewise, in A. fatua containing pots the separate application of PAO1 and T-MN6 resulted in 20 and 18\% reduction as compared to controls but the effect of interactive application was more pronounced resulting in $28 \%$ root length reduction as compared to their sole application.

Data regarding fresh biomass revealed similar trend. The separate application resulted in considerable reduction 14 and $11 \%$ of fresh biomass of $P$. minor as compared to controls and the consortium application yielded $29 \%$ reduction in fresh biomass as compared to sole applications. However, the effect of their single application was statistically non-significant to each other. Similarly, in A. fatua infested pots the separate application of PAO1 and T-MN6 resulted in 20 and 15\% reduction as compared to containing control. The synergistic application resulted in maximum $31 \%$ fresh biomass reduction as compared to sole applications.

Table 1. Effect of plant antagonistic rhizobacteria and fungi on suppression of shoot length, root length and fresh biomass of test weeds.

\begin{tabular}{|c|c|c|c|c|c|c|}
\hline Treatment & $\begin{array}{l}\text { A. fatua } \\
\text { Shor }\end{array}$ & $\begin{array}{l}\text { P. minor } \\
(\mathrm{cm})\end{array}$ & $\begin{array}{r}\text { A. fatua } \\
\text { Roo }\end{array}$ & $\begin{array}{l}\text { P. minor } \\
\text { m) }\end{array}$ & $\begin{array}{l}\text { A. fatua } \\
\text { Fresh bi }\end{array}$ & $\begin{array}{l}\text { P. minor } \\
\left(\mathrm{g} \mathrm{pot}^{-1}\right)\end{array}$ \\
\hline Control & $39.7^{\mathrm{a}}$ & $29.07^{\mathrm{c}}$ & $13.7^{\mathrm{a}}$ & $12.33^{\mathrm{b}}$ & $34.80^{\mathrm{a}}$ & $26.47^{c}$ \\
\hline PAO1 & $31.7^{\mathrm{b}}$ & $23.20^{\mathrm{e}}$ & $11.0^{c}$ & $10.63^{c}$ & $27.87^{\mathrm{b}}$ & $22.87^{\mathrm{e}}$ \\
\hline T-MN6 & $33.6^{\mathrm{b}}$ & $25.87^{\mathrm{d}}$ & $11.2^{c}$ & $10.87^{c}$ & $29.43^{b}$ & $23.47^{\mathrm{d}}$ \\
\hline PAO1+T-MN6 & 23.9de & $20.30^{\mathrm{f}}$ & $9.9^{\mathrm{d}}$ & $9.60^{\mathrm{d}}$ & $23.93^{\mathrm{d}}$ & $18.70^{\mathrm{f}}$ \\
\hline
\end{tabular}

Values sharing same letter(s) are statistically non-significant with each other at $(\mathrm{P}<0.05)$. PA01, Pseudomonas aeruginosa and T-MN6, Trichoderma harzianum T-MN6. 


\section{Growth and yield response of wheat}

Data indicated that separate application of PAO1 and T-MN6 increased shoot length of wheat grown without weeds up to 16 and $13 \%$ respectively as compared to control but the effect was more significant with the combined application of PAO1 and T-MN6 resulting in $21 \%$ increased shoot length as compared to sole applications. Similarly, in P. minor infested wheat the individual application increased shoot length up to 14 and $11 \%$ as compared to $P$. minor containing control. The maximum increase $(17 \%)$ in this case was obtained when PAO1 and T-MN6 were applied together. Likewise, in A. fatua infested pots the sole application of PAO1 and Trichoderma sp. resulted in 13 and $11 \%$ increased shoot length of wheat as compared to A. fatua containing control. The integrative application of PAO1 and T-MN6 gave maximum (15\%) increase in shoot length as compared to alone applications in $A$. fatua infested wheat (Table 2).

It was observed that the single application of PAO1 and TMN6 significantly improved the root length of wheat grown without weeds about 21 and $44 \%$ respectively over weed free control (Table 2). But the combined application gave maximum results in terms of $75 \%$ increase in root length of wheat as compared to sole application. In Phalaris minor containing pots 29 and 54\% increase was observed in root length of wheat with the single application of PAO1 and T-MN6 over Phalaris minor containing control. The maximum increase $74 \%$ was observed with the consortium application as compared to the sole application of PAO1 and T-MN6 Similarly, in Avena fatua containing pots the individual application of PAO1 and T-MN6 caused an increase of 29 and 54\% respectively as compared to Avena fatua containing control. However, the synergistic effect of PAO1 and T-MN6 resulted in maximum $68 \%$ increase in root length as compared to the sole application.

Data illustrated that separate application of PAO1 and T-MN6 increased spike length of wheat grown without weeds up to 20 and $16 \%$ respectively as compared to control but the effect was more significant with the combined application of PAO1 and T-MN6 resulting in 51\% increased spike length as compared to sole applications. Similarly, in P. minor infested wheat the individual application increased spike length up to 17 and $14 \%$ as compared to $P$. minor containing control (Table 2). The maximum increase ( $40 \%)$ in this case was obtained when PAO1 and T-MN6 were applied together. Likewise, in A. fatua infested pots the sole application of PAO1 and T-MN6 resulted in 15 and 13\% increased spike length of wheat as compared to A. fatua containing control. The integrative application of PAO1 and T-MN6 gave maximum (35\%) increase in spike length as compared to alone applications in $A$. fatua infested wheat.

The obtained data specified increasing trend in total tillers of wheat grown with and without weeds (Table 2). Single inoculation of PAO1 and T-MN6 increased number of total tillers up to 19 and $14 \%$ under weed free wheat conditions as compared to control. But the co-inoculation maximally $(33 \%)$ increased the number of total tillers per pot as compared to their sole inoculation. In case of $P$. minor containing pots the individual application of PAO1 and TMN6 resulted in 17 and 13\% increase in number of total tillers as compared to P. minor containing control. Whereas, the combined application gave maximum results in terms of $27 \%$ increased number of total tillers as compared to sole applications. In A. fatua infested pots alone application of PAO1 and T-MN6 increased the number of total tillers up to 15 and $11 \%$ respectively as compared to A. fatua containing control. The combined application in this case resulted in $23 \%$ increase in number of total tillers as compared to their alone applications.

It was observed that the single application of PAO1 and TMN6 significantly improved the number of productive tillers of wheat per pot grown without weeds about 33 and $21 \%$ respectively over weed free control (Table 2). But the combined application gave maximum results in terms of $63 \%$ increase in number of productive tillers of wheat as compared to sole applications. In Phalaris minor containing pots 29 and 19\% increase was observed in number of productive tillers of wheat with the single application of PAO1 and T-MN6 over Phalaris minor containing control. The maximum increase $48 \%$ was observed with the consortium application as compared to the sole application of PAO1 and T-MN6 Similarly, in Avena fatua containing pots the individual application of PAO1 and T-MN6 caused an increase of 22 and $47 \%$ respectively as compared to Avena fatua containing control. However, the synergistic effect of PAO1 and resulted in maximum 39\% increase in productive tillers as compared to the sole application.

Obtained data depicted that separate application of PAO1 and T-MN6 increased 1000 grains weight of wheat grown without weeds up to 21 and $16 \%$ respectively as compared to control but the effect was more significant with the combined application of PAO1 and T-MN6 resulting in 33\% increased spike length as compared to sole applications. Similarly, in P. minor infested wheat the individual application increased 1000 grains weight up to 16 and $14 \%$ as compared to $P$. minor containing control. The maximum

Table 2. Effect of plant antagonistic rhizobacteria and fungi on growth and yield parameters of wheat.

\begin{tabular}{|c|c|c|c|c|c|c|c|c|c|}
\hline \multirow{2}{*}{$\begin{array}{l}\text { Treatment } \\
\text { Control }\end{array}$} & \multicolumn{3}{|c|}{$\begin{array}{l}\text { Weed free } P \text {. minor } A \text {. fatua } \\
\text { Wheat plant shoot length }(\mathrm{cm})\end{array}$} & \multicolumn{3}{|c|}{$\begin{array}{c}\text { Weed free } P \text {. minor A. fatua } \\
\text { Wheat plant root length }(\mathrm{cm})\end{array}$} & \multicolumn{3}{|c|}{$\begin{array}{l}\text { Weed free P. minor } A \text {. fatua } \\
\text { Wheat spike length }(\mathrm{cm})\end{array}$} \\
\hline & $68.80^{\text {cd }}$ & $66.83^{\mathrm{fg}}$ & $61.17^{\mathrm{i}}$ & $16.67^{\mathrm{f}}$ & $14.50^{\mathrm{g}}$ & $13.27^{\mathrm{g}}$ & $9.60^{\mathrm{d}}$ & $8.40^{\mathrm{fg}}$ & $7.67^{\mathrm{g}}$ \\
\hline PAOI & $79.67^{\mathrm{b}}$ & $76.33^{\text {de }}$ & $69.13 \mathrm{~g}^{\mathrm{h}}$ & $20.17^{\mathrm{de}}$ & $18.70^{\mathrm{e}}$ & $17.07^{\mathrm{f}}$ & $11.50^{\mathrm{bc}}$ & $9.87^{\mathrm{de}}$ & $8.80^{\mathrm{ef}}$ \\
\hline T-MN6 & $77.67^{\mathrm{c}}$ & $74.00^{\mathrm{ef}}$ & $67.67^{\mathrm{h}}$ & $24.07^{\mathrm{b}}$ & $22.33^{c}$ & $20.40^{\mathrm{d}}$ & $11.17^{\mathrm{c}}$ & $9.57^{\mathrm{d}-\mathrm{f}}$ & $8.67^{\circ}$ \\
\hline PAO1+ T-MN6 & $83.33^{\mathrm{a}}$ & $78.40^{\text {cd }}$ & $70.50^{\mathrm{fg}}$ & $29.23^{\mathrm{a}}$ & $25.30^{\mathrm{b}}$ & $22.33^{\mathrm{c}}$ & $14.50^{\mathrm{a}}$ & $11.73^{b}$ & $10.37^{c}$ \\
\hline Treatment & \multicolumn{3}{|c|}{ No. of total tillers $\left(\right.$ pot $\left.^{-1}\right)$} & \multicolumn{3}{|c|}{ No. of productive tillers $\left(\mathrm{pot}^{-1}\right)$. } & \multicolumn{3}{|c|}{1000 grains weight ( $\mathrm{g} \mathrm{pot}^{-1}$ ) } \\
\hline Control & $12.00^{\mathrm{cd}}$ & $10.00^{\mathrm{ef}}$ & $8.67^{\mathrm{f}}$ & $8.00^{\mathrm{de}}$ & $7.00^{\mathrm{ef}}$ & $6.00^{\mathrm{f}}$ & $40.00^{\mathrm{e}}$ & $36.50^{\mathrm{fg}}$ & $34.33^{\mathrm{h}}$ \\
\hline PAO1 & $14.33^{b}$ & $11.67 \mathrm{de}$ & $10.00^{\mathrm{de}}$ & $10.67^{\mathrm{cd}}$ & $9.00^{\text {de }}$ & $7.33^{\mathrm{ef}}$ & $48.50^{\mathrm{b}}$ & $42.17^{\mathrm{e}}$ & $39.00^{\mathrm{fg}}$ \\
\hline T-MN6 & $13.67^{\mathrm{bc}}$ & $11.33^{\text {de }}$ & $9.67^{\mathrm{ef}}$ & $9.67^{\mathrm{cd}}$ & $8.33^{\text {ef }}$ & $7.00^{\mathrm{ef}}$ & $46.30^{c}$ & $41.67^{\mathrm{f}}$ & $38.00^{\mathrm{gh}}$ \\
\hline PAO1+T-MN6 & $16.00^{\mathrm{a}}$ & $12.67^{\mathrm{b}}$ & $10.67^{\mathrm{bc}}$ & $13.00^{\mathrm{a}}$ & $10.33^{b}$ & $8.33^{\mathrm{bc}}$ & $53.30^{\mathrm{a}}$ & $45.83^{\mathrm{c}}$ & $42.17^{\mathrm{d}}$ \\
\hline
\end{tabular}

Values sharing same letter(s) are statistically non-significant with each other at $(\mathrm{P}<0.05)$. PA01, Pseudomonas aeruginosa and T-MN6, Trichoderma harzianum T-MN6. 
increase $(26 \%)$ in this case was obtained when PAO1 and T-MN6 were applied together. Likewise, in A. fatua infested pots the sole application of PAO1 and T-MN6 resulted in 14 and $11 \%$ increased 1000 grains weight of wheat as compared to A. fatua containing control. The integrative application of PAO1 and T-MN6 gave maximum (23\%) increase in 1000 grains weight as compared to alone applications in A. fatua infested wheat (Table 2).

\section{Chemical parameters of wheat}

Plants inoculated with PAO1 and T-MN6 alone and in combination showed improved nitrogen, phosphorous and potassium contents in wheat grains as compared to respective controls in weedy and weed free conditions as well (Table 3).

Data regarding nitrogen contents in grains of wheat grown without weeds indicated that alone application of PAO1 and TMN6 increased grain nitrogen content up to 18 and $15 \%$ respectively as compare to control but the effect was more significant with the combined application of PAO1 and T-MN6 resulting in $27 \%$ increased grain nitrogen content as compared to sole applications. Similarly, in P. minor infested wheat the individual application increased grain nitrogen content up to 14 and $11 \%$ as compared to $P$. minor containing control. The maximum increase $(20 \%)$ in this case was obtained when PAO1 and T-MN6 were applied together. Likewise, in A. fatua infested pots the sole application of PAO1 and T-MN6 resulted in 12 and $10 \%$ increased grain nitrogen content of wheat as compared to A. fatua containing control. The integrative application of PAO1 and T-MN6 gave maximum $(19 \%)$ increase in grain nitrogen content as compared to alone applications in A. fatua infested wheat.

It was observed that the single application of PAO1 and TMN6 considerably enriched the phosphorous concentration in grains of wheat grown without weeds about 13 and $29 \%$ respectively over weed free control. But the combined application gave maximum results in terms of $47 \%$ increase in phosphorous concentration in grains of wheat as compared to sole application. In Phalaris minor containing pots there was 12 and 21\% increase observed in phosphorous contents in grains of wheat with the single application of PAO1 and T-MN6 over Phalaris minor containing control. The maximum increase $30 \%$ was observed with the consortium application as compared to the sole application of PAO1 and T-MN6. Similarly, in Avena fatua containing pots the individual application of PAO1 and T-MN6 caused an increase of 17 and $25 \%$ respectively as compared to Avena fatua containing control. However, the synergistic effect of PAO1 and T-MN6 resulted in maximum $30 \%$ increase in phosphorous concentration in grains as compared to the sole application.

In weed free conditions alone inoculation of PAO1 and T-MN6 resulted in 16 and $12 \%$ increased potassium concentration in grains as compared to control. Whereas, combined application in this case gave maximum $(26 \%)$ increase in grain potassium concentration as compared to sole applications. However, in P. minor containing pots the sole application of PAO1 and T-MN6 resulted in 14 and $12 \%$ increase in grain potassium concentration as compared to control infested with $P$. minor, with the combined application resulting in $18 \%$ increase as compared to sole applications. In A. fatua infested pots sole inoculation resulted in 12 and $10 \%$ increase in grain potassium contents as compared to control containing $A$. fatua. The combined application in this case resulted in $17 \%$ increased potassium contents in wheat grains as compared to sole applications.

\section{Physiological parameters of wheat}

Physiological parameters of wheat were improved significantly upon inoculation with PAO1 and T-MN6 alone and in synergism as compared to control in weed infested and weed free conditions. Maximum (24\%) improvement in chlorophyll (SPAD value) contents of wheat was observed with consortium application of PAO1 and T-MN6 as compared to sole inoculation. Whereas, sole application of PAO1 and T-MN6 resulted in 16 and 13\% increased chlorophyll contents of wheat as compared to control under weed free conditions. However, in P. minor infested conditions sole application of PAO1 and T-MN6 resulted in 15 and 12\% improvement in chlorophyll contents as compared to $P$. minor infested control. The combined application of PAO1 and T-MN6 gave maximum (19\%) chlorophyll contents as compared to sole inoculation. Similarly, in $A$, fatua containing pots 13 and $10 \%$ increase in chlorophyll contents was observed with sole application of PAO1 and T-MN6 as compared to A. fatua containing control. The combined application resulted in $16 \%$ improvement in chlorophyll contents as compared to sole applications (Figure 1).

Data regarding relative water contents of wheat grown without weeds indicated that alone application of PAO1 and T-MN6 increased relative water contents up to 18 and $14 \%$ respectively as compared to control but the effect was more significant with the combined application of PAO1 and T-MN6 resulting in $24 \%$ increased relative water contents as compared to sole applications. Similarly, in $P$. minor infested wheat the individual application increased grain relative water contents up to 14 and $12 \%$ as compared to $P$. minor containing control. The maximum increase $(20 \%)$ in this case was obtained when PAO1 and T-MN6 were applied together. Likewise, in A. fatua infested pots the sole application of PAO1 and T-MN6 resulted in 12 and $11 \%$ increased relative water contents of wheat as compared to A. fatua containing control. The integrative application of PAO1 and T-MN6 gave maximum $(17 \%)$ increase in relative water contents as compared to alone applications in A. fatua infested wheat (Figure 2).

\section{Discussion}

Present study highlighted the bioherbicidal potential of previously isolated and pre-characterised Pseudomonas aeruginosa

Table 3. Effect of plant antagonistic rhizobacteria and fungi on NPK contents in grains of infested and weed free wheat.

\begin{tabular}{|c|c|c|c|c|c|c|c|c|c|}
\hline Treatment & Weed free & $\begin{array}{l}\text { P. mino } \\
\operatorname{ain} N\end{array}$ & 4. fatua & Weed free & $\begin{array}{l}P . \min 0 \\
\text { rain } \mathrm{P}\end{array}$ & A. fatua & Weed fre & $\begin{array}{l}\text { P. mino } \\
\text { ain } \mathrm{K}\end{array}$ & 4. fatua \\
\hline Control & $2.21^{\mathrm{cd}}$ & $1.98^{\mathrm{fg}}$ & $1.91^{\mathrm{g}}$ & $0.24^{\mathrm{fg}}$ & $0.23^{\mathrm{g}}$ & $0.21^{\mathrm{h}}$ & $1.52^{\mathrm{e}-\mathrm{g}}$ & $1.47^{\mathrm{gh}}$ & $1.42^{\mathrm{h}}$ \\
\hline PAO1 & $2.60^{\mathrm{b}}$ & $2.27^{\mathrm{de}}$ & $2.13^{\mathrm{e}-\mathrm{g}}$ & $0.27^{\mathrm{cd}}$ & $0.26^{\mathrm{d}-\mathrm{f}}$ & $0.25^{\mathrm{e}-\mathrm{g}}$ & $1.76^{\mathrm{b}}$ & $1.67^{\mathrm{e}}$ & $1.5 \mathrm{gef}^{\mathrm{ef}}$ \\
\hline T-MN6 & $2.55^{\mathrm{c}}$ & $2.20^{\mathrm{ef}}$ & $2.10^{\mathrm{fg}}$ & $0.31^{\mathrm{b}}$ & $0.28 \mathrm{c}$ & $0.26^{c-e}$ & $1.70^{\mathrm{d}}$ & $1.65^{\mathrm{fg}}$ & $1.57^{\mathrm{gh}}$ \\
\hline PAO1+ T-MN6 & $2.80^{\mathrm{a}}$ & $2.38^{\mathrm{cd}}$ & $2.27^{\mathrm{d}}$ & $0.35^{\mathrm{a}}$ & $0.30^{\mathrm{b}}$ & $0.27^{c-d}$ & $1.92^{\mathrm{a}}$ & $1.74^{\mathrm{cd}}$ & $1.66^{\mathrm{bc}}$ \\
\hline
\end{tabular}

Values sharing same letter (s) are statistically non-significant with each other at $(\mathrm{P}<0.05)$. PAO1, Pseudomonas aeruginosa and T-MN6, Trichoderma harzianum T-MN6. 
PAO1 in conjunction with Trichoderma harzianum T-MN6 against two wheat associated weeds (Phalaris minor and Avena fatua) and wheat growth promotion under weed free and weed infested pot conditions. The Pseudomonas aeruginosa PAO1 strain used in current study had already been characterised to produce phytotoxic substances, phosphate solubilisation, weeds suppression with noninhibitory effects on wheat in our previous study (Abbas et al., 2017a). The key objective of this study was to evaluate the synergistic effect of Pseudomonas aeruginosa PAO1strain and Trichoderma harzianum T-MN6 on suppression of wheat associated weeds and growth and yield enhancement of wheat. Inoculation with PAO1 and T-MN6 significantly reduced growth parameters (shoot length, root length and fresh biomass) of both weeds alone and in combination. Maximum suppression in growth parameters of both weeds was observed with combined use of PAO1 and TMN6 followed by PAO1 and T-MN6 respectively. However, the effect of PAO1 and T-MN6 remained non-significant to each other. The inhibition of growth parameters of both weeds might be due to the ability of PAO1 and T-MN6 to competitively colonise and produce phytotoxic metabolites in the rhizosphere. In this study maximum inhibition was observed in Phalaris minor than Avena fatua. This might be due the differential colonisation of PAO1 in roots enabling more targeted weed control (Kennedy et al., 2001) and higher suppression of Phalaris minor (Table 1) is related to better colonisation of the applied strains in the rhizosphere of $P$. minor (Abbas et al., 2017a). Whereas, the low inhibition of Avena fatua in our study is related to exposure to increased competition of introduced strains with the indigenous microbes and fluctuations in environmental conditions affecting the survival and efficacy of these strains (Kremer and Kennedy, 1996; Horwath et al., 1998). Similar to our findings are the results reported by Harris and Stahlman (1996) they reported less reduction of wheat associated jointed goatgraas, Japanese brome and downy brome weeds in non-sterile than sterile soil. In nut shell our results depicted significant reduction in growth parameters of both weeds upon inoculation with PAO1 and T-MN6. These results are supported by other studies: as Shukorjuraimi et al. (2005) reported reduced growth and dry weight of barnyard grass ecotypes PK-04, L-01 and B-04 upon application of Exserohilum longirostratum. Similarly, Weissmann (2003) showed strong bioherbicidal activity of
Serratia plymuthica, strain A153 against multiple broad-leaved weeds upon foliar spray. Li and Kremer (2006) reported reduction in Ipomea species and Convolvolus arvensis weeds in wheat and soybean upon inoculation with Pseudomonas fluorescens.

In our study the biological control potential of T-MN6 is found to be less than PAO1. This might be due the reason that bacteria took advantage over Trichoderma by showing accelerated growth rates and aggressive colonisation with simple growth requirements (Lee et al., 2003). Our results are in agreement with (Javaid and Sajjad, 2011) they reported a significant inhibition of shoot and root length of Avena fatua upon application of culture filtrates of four Trichoderma spp. namely T. harzianum, T. pseudokoningii, T. reesei and T. viride. Siddiqui et al. (2010), explored fungal involvement in Chenopodium album L. suppression under wheat field conditions using Alternaria alternata. Application of Alternaria alternata significantly $(90 \%)$ reduced the biomass of Chenopodium album L. Akbar and Javaid (2012) reported that application of fungal filtrate of four Drechslera sp. reduced germination and growth attribute of two wheat associated weeds Chenopodium album L. and Avena fatua L.

In this study, significant reduction has been observed in growth, physiology and chemical parameters of wheat grown with weeds as compared to weed free conditions. However, the applied strains ameliorated the negative effects of weeds on wheat crop up to a significant extent. The applied strains were found non-inhibitory to wheat. This may be on part due to the least sensitivity of wheat to the phytotoxic metabolites of applied strains (Owen and Zdor, 2001) rendering increased reduction of weeds growth resultantly, on other part is due to the production of plant growth promoting substances by these strains. Improvement in weeds infected wheat growth due to synthesis of plant growth promoting substances in rhizosphere by rhizobacteria might have evoked the competitive ability of crop against weeds (Zahir et al., 2004; Mejri et al., 2010). Similar to bacterial strain T-MN6 might have triggered the systemic or localised resistance responses in crop through production of elicitor-like substances (Harman et al., 2004; Ali et al., 2017). The production of other plant growth promoting substances siderophores, VOCs and synthesis of IAA by Trichoderma spp. are also wellknown possible reasons of plant growth promotion under biotic and abiotic stresses (Vinale et al., 2008).

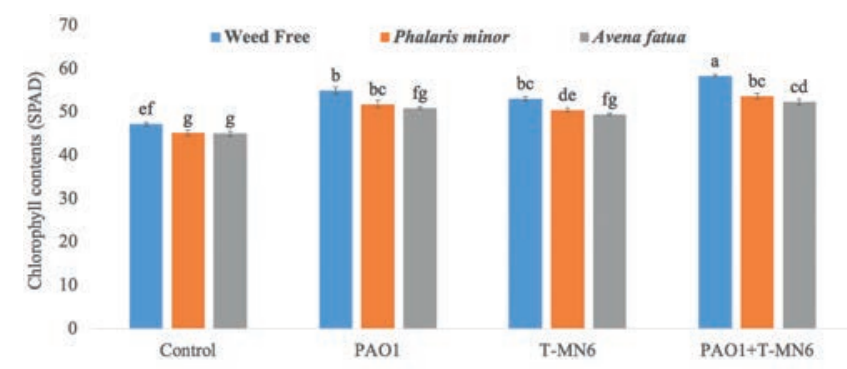

Figure 1. Effect of plant antagonistic rhizobacteria and fungi on chlorophyll contents of infested and weed free wheat. PAO1, Pseudomonas aeruginosa and T-MN6, Trichoderma harzianum T-MN6. Values sharing same letter(s) are statistically non-significant with each other at $(\mathrm{P}<0.05)$.

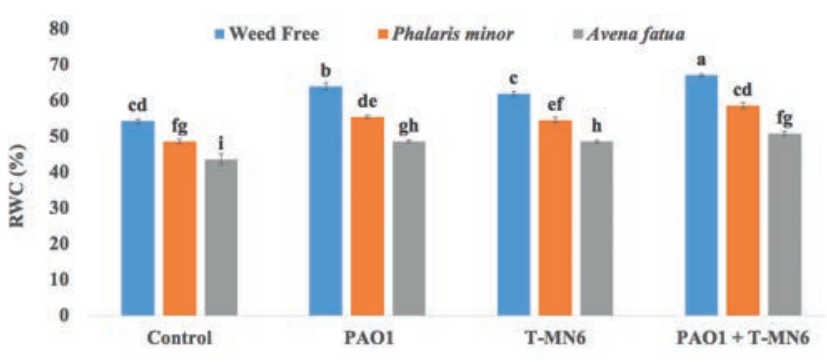

Figure 2. Effect of plant antagonistic rhizobacteria and fungi on relative water contents of infested and weed free wheat. PAO1, Pseudomonas aeruginosa and T-MN6 = Trichoderma harzianum T-MN6. Values sharing same letter(s) are statistically non-significant with each other at $(P<0.05)$. 
In our study, T-MN6 significantly improved root growth of wheat in weed free and weed infested conditions probably in higher amounts than bacterial strain. This may be due to the production of IAA and its derivatives that has promoted root length of wheat. These results are in accordance with Contreras-Cornejo et al. (2009) they reported, increased lateral roots of Arabidopsis by Trichoderma virens Gv29.8 and T. atroviride IMI206040 through the production of IAA and its equivalent compounds. Similarly, data revealed an increased phosphorous content in grains of wheat in pots inoculated with T-MN6 than PAO1 in weed free and weedy conditions as well. However, the trend was as follows: PAO1 + TMN6 > T-MN6 > PAO1. This may be due to increased production of IAA by both microorganisms that in turn might have modified root architecture, resulting in increased root mass and increased surface area available for microbial colonisation and larger root system enhancing nutrient uptake by plants (Spaepen et al., 2007; Berg, 2009; Contreras-Cornejo et al., 2009; Puia et al., 2017). Increased phosphorous contents of wheat grains are also obvious from the fact that certain plant growth promoting rhizobacteria and fungi have the ability to solubilise inorganic phosphate from the soil hence results in increased availability of phosphorous to plants leading to increased growth and yield (Soriano et al., 2009; Candido et al., 2013; Ali et al., 2017). The applied strains in our study also improved chlorophyll and relative water contents of infested as well weed free wheat. The underlying mechanism is the improved availability of iron to main crop by sequestration of iron through production of siderophores by rhizobacteria (Yang et al., 2009) and by Trichoderma (Segarra et al., 2010), as iron is the key component of chlorophyll molecule. So enhanced availability of iron may have increased the chlorophyll contents of wheat grains. Due to the host specific nature of the applied strains, these may have scavenged iron from the environment rendering it unavailable for the competing plants and even microbes.

Overall, the applied strains improved growth, yield and physiology of wheat while significantly inhibiting wheat associated weeds (A. fatua and P. minor). Since the maximum improvement in growth and yield parameters were reflected by the combined use of PAO1 and T-MN6 so, our hypothesis that synergistic use of plant antagonistic rhizobacteria and fungi may improve growth and yield of wheat by inhibiting growth of associated weeds is advocated from the obtained data.

\section{Conclusions}

This study concluded that Pseudomonas aeruginosa PAO1 in combination with Trichoderma harzianum T-MN6 have a great potential to suppress wheat associated weeds along with enhancement in growth, physiology and yield of wheat. The above-mentioned strains through multiple mechanisms can improve the competitive ability of main crops against weeds. Specifically, this study has demonstrated the synergistic use of bacterial and fungal strains in biological weeds suppression and improvement in wheat growth. Therefore, further in-depth studies are required to develop these potent biological agents into suitable formulations in order to achieve environmental and agricultural sustainability, food security and resource conservation.

\section{References}

Abbas T, Zahir AZ, Naveed M, 2017a. Bioherbicidal activity of allelopathic bacteria against weeds associated with wheat and their effects on growth of wheat under axenic conditions. BioControl. 62:719-30.

Abbas T, Zahir AZ, Naveed M, Aslam Z, 2017b. Biological control of broad-leaved dock infestation in wheat using plant antagonistic bacteria under field conditions. Environ. Sci. Pollut. Res. 24:14934-44.

Ali MA, Naveed M, Mustafa A, Abbas, A, 2017. The good, the bad and the ugly of rhizosphere microbiome. In: Probiotics and Plant Health. Springer, Singapore, pp 253-290.

Ahemad M, Kibret M, 2014. Mechanisms and applications of plant growth promoting rhizobacteria: Current perspective. J. King Saud Uni. Sci. 26:1-20.

Akbar M, Javaid A, 2012. Herbicidal activity of fungal culture filtrates against Chenopodium album L. and Avena fatua L. J. Anim. Plant. Sci. 22:977-82.

Berg G, 2009. Plant-microbe interactions promoting plant growth and health: perspectives for controlled use of microorganisms in agriculture. Appl. Microbiol. Biotechnol. 84:11-8.

Candido V, Campanelli G, D'Addabbo T, Castronuovo D, Renco M, Camele I, 2013. Growth and yield promoting effect of artificial mycorrhization combined with different fertiliser rates on field-grown tomato. Ital. J. Agron. 8:22.

Contreras-Cornejo HA, Macías-Rodríguez L, Cortés-Penagos C, López-Bucio J, 2009. Trichoderma virens, a plant beneficial fungus, enhances biomass production and promotes lateral root growth through an auxin-dependent mechanism in Arabidopsis. Plant. Physiol. 149:1579-92.

Crone EE, Marler M, Pearson DE, 2009. Non-target effects of broadleaf herbicide on a native perennial forb: a demographic framework for assessing and minimising impacts. J. Appl. Ecol. 46:673-82.

Coste S, Christopher B, Céline L, Eric M, Amélie R, Andrew D, 2010. Assessing foliar chlorophyll contents with the SPAD502 chlorophyll meter: a calibration test with thirteen tree species of tropical rainforest in French Guiana. Ann. Forest. Sci. 67:607.

FAO, 2014. FAO statistical year book. Available from: http://faostat3.fao.org

Ghorbani R, Leifert C, Seel W, 2005. Biological control of weeds with antagonistic plant pathogens. Adv. Agron. 86:191-225.

Hanada RE, Pomella AWV, Soberanis W, Loguercio LL, Pereira JO, 2009. Biocontrol potential of Trichoderma martiale against the blackpod disease (Phytophthora palmivora) of cacao. Biol. Control. 50:143-9.

Howell CR, 2003. Mechanisms employed by Trichoderma species in the biological control of plant diseases: the history and evolution of current concepts. Plant. Dis. 87:4-10.

Heraux FMG, Hallett SG, Ragothama KG, Weller SC, 2005. Composted chicken manure as a medium for the production and delivery of Trichoderma virens for weed control. Hort. Sci. 40:1394-7.

Harman GE, Howell CR, Viterbo A, Chet I, Lorito M, 2004. Trichoderma species opportunistic, avirulent plant symbionts. Nat. Rev. Microbiol. 2:43-56. 
Harris PA, Stahlman PW, 1996. Soil bacteria as selective biological control agents of winter annual grass weeds in winter Triticum aestivum. Appl. Soil. Ecol. 3:275-81.

Horwath W, Elliott LF, Lynch JM, 1998. Influence of soil quality on the function of inhibitory rhizobacteria. Lett. Appl. Microbiol. 26:87-92.

King E, Ward M, Raney D, 1954. Two simple media for the demonstration of Pycyanin and Xuorescein. J. Lab. Clinic. Med. 44:301-7.

Haas D, Défago G, 2005. Biological control of soil-borne pathogens by fluorescent pseudomonads. Nat. Rev. Microbiol. 3:307-19.

Javaid A, Akbar M, 2012. Evaluation of herbicidal potential of fungal metabolites against Phalaris minor. Afr. J. Microbiol.Res. 6:4053-7.

Javaid A, Adrees H, 2009. Parthenium management by cultural filtrates of phytopathogenic fungi. Nat. Prod. Res. 23:1541-51.

Khan I, Hassan G, Marwat KB, 2002. Efficacy of Different Herbicides for Controlling Weeds in Wheat Crop. Weed Dynamics and Herbicides. Pak. J. Weed Sci. Res. 8:41-7.

Kremer RJ, Kennedy AC, 1996. Rhizobacteria as biological control agents of weeds. Weed Technol. 10:601-9.

Kennedy AC, Johnson BN, Stubbs TL, 2001. Host range of a deleterious rhizobacterium for biological control of downy brome. Weed Sci. 49:792-7.

Li J, Kremer RJ, 2006. Growth response of weed and crop seedlings to deleterious rhizobacteria. Biol. Control. 39:58-65.

Lee HB, Kim CJ, Kim JS, Hong KS, Cho KY, 2003. A bleaching herbicidal activity of methoxyhygromycin (MHM) produced by an (Actinomycete strain Streptomyces) sp. 8E-12. Lett. Appl. Microbiol. 36:387-91.

Mejri D, Gamalero E, Tombolini R, Musso C, Massa N, Berta G, 2010. Biological control of great brome (Bromus diandrus) in durum wheat (Triticum durum): specificity, physiological traits and impact on plant growth and root architecture of fluorescent pseudomonad strain X33d. BioControl. 55:561-72.

Mayak S, Tirosh T, Glick BR, 2004. Plant growth-promoting bacteria that confer resistance to water stress in tomatoes and peppers. Plant Sci. 166:525-30.

Mustafa A, Naveed M, Saeed Q, Ashraf MN, Hussain A, Abbas T, Kamran M, Nan S, Minggang X. 2019. Application potentials of plant growth promoting rhizobacteria and fungi as an alternative to conventional weed control methods. In: Crop Production. IntechOpen., London, UK.

Noorka IR, Shahid SA, 2013. Use of Conservation Tillage System in Semiarid Region to Ensure Wheat Food Security in Pakistan. Development in Soil Salinity Assessment and Reclamation, Springer Book.

Owen A, Zdor R, 2001. Effect of cyanogenic rhizobacteria on the growth of velvetleaf (Abutilon theophrasti) and corn (Zea mays L.) in autoclaved soil and the influence of supplemental glycine. Soil Biol. Biochem. 33:801-9.

Oerke EC, 2006. Crop losses to pests. J. Agric. Sci.144:31-43.

Puia C, Vidican R, Szabó G, Stoian V, 2017. Potential of biofertilisers to improve performance of local genotype tomatoes. Ital. J. Agron. 12:838.

Shukorjuraimi A, Tasrif A, Kadir J, Napis J, Sastroutomo SS, 2005. Phytotoxicity and field efficacy of Exserohilum longirostra for the control of barnyard grass. Biotropica 24:20-9.

Siddiqui I, Bajwa R, Javaid A, 2010. Mycoherbicidal potential of Alternaria alternata for management of Chenopodium album under field condition. Afr. J. Biotechnol. 9:8308-12.

Spaepen S, Vanderleyden J, Remans R, 2007. Indole-3-acetic acid in microbial and microorganism-plant signaling. FEMS Microbiol. Rev. 31:425-48.

Segarra G, Casanova E, Aviles M, Trillas I, 2010. Trichoderma asperellum strain T34 controls Fusarium wilt disease in tomato plants in soilless culture through competition for iron. Microb. Ecol. 59:141-9.

Sturz AV, Christie BR, 2003. Beneficial microbial allelopathies in the root zone: the management of soil quality and plant disease with rhizobacteria. Soil Till. Res. 72:107-23.

Steel RGD, Torrie JH, Dicky DA, 1997. Principles and procedures of statistics: a biometrical approach. 3rd edn. McGraw Hill Book International Co., Singapore.

Sahebani N, Hadavi N, 2008. Biological control of the root-knot nematode Meloidogyne javanica by Trichoderma harzianum. Soil Biol. Biochem. 40:2016-20.

Tabaglio V, Marocco A, Schulz M, 2013. Allelopathic cover crop of rye for integrated weed control in sustainable agroecosystems. Ital. J. Agron. 8:e5.

Vargas RDF, O'Hara GW, 2006. Isolation and characterisation of rhizosphere bacteria with potential for biological control of weeds in vineyards. J. Appl. Microbiol. 100:946-54.

Vinale F, Sivasithamparam K, Ghisalberti EL, Marra R, Barbetti MJ, Li H, Woo SL, 2008. A novel role for Trichoderma secondary metabolites in the interactions with plants. Physiol. Mol. Plant Pathol. 72:80-6.

Vyas P, Gulati A, 2009. Organic acid production in vitro and plant growth promotion in maize under controlled environment by phosphate-solubilising fluorescent Pseudomonas. BMC Microbiol. 22:1-15.

Weissmann R, Uggla C, Gerhardson B, 2003. Field performance of a weed-suppressing Serratia plymuthica strain applied with conventional spraying equipment. Biol. Control. 48:725-42.

Yang J, Kloepper JW, Ryu CM, 2009. Rhizosphere bacteria help plants tolerate abiotic stress. Trends Plant Sci. 14:1-4. 